\title{
DEFOE Y COETZEE
}

Diego Sheinbaum*

$\mathrm{E}_{\text {s el momento en que el escritor }}$ galardonado con el premio Nobel se dirige al auditorio, al mundo, urbi et orbi, como diría Joseph Brodsky. La noche de la literatura en que se espera que su hijo pródigo o hija predilecta le rinda honores y defienda su lugar en el mundo. Como en los premios Óscares, es una noche en que se habla de las deudas contraídas y se dan las gracias. Pero el escritor sudafricano no hizo nada de esto. No dio respuestas ni indicaciones claras o hizo afirmaciones existenciales sobre la escritura. En vez de un discurso leyó un cuento. En el cuento Robinson Crusoe, el protagonista, tiene una misteriosa relación con un hombre que le manda reportes de todas partes de la isla y sobre los temas más extraños: patos que engañan a otros patos, guillotinas y anécdotas del año de la peste. Robinson lee sus reportes y los compara con la historia de su vida: la experiencia del naufragio en la isla desierta.

¿Por qué nos contaba eso Coetzee?, me pregunté mientras pensaba en el discurso de Joseph Brodsky, en cómo le había rendido culto a Auden, Akhmatova, Frost y después había hablado de la poesía casi en términos religiosos como un caparazón de la condición única, irrepetible, de cada ser humano. Recordé sus palabras sobre el verso como una forma adictiva de aceleración de la conciencia, y la lectura, no como un monólogo, sino como un diálogo en un plano de igualdad intelectual. ${ }^{1}$ Todas estas reflexiones estaban ausentes en el cuento de Coetzee. Ahí sólo estaba Robinson y el misterioso hombre que le

* Escritor.

${ }^{1}$ Joseph Brodsky, Nobel Lecture, (www.nobelprize, org.), december 8, 1987. 
mandaba reportes; cuando hablaba de literatura las referencias eran oscuras, Robinson mencionaba a los escritores como caníbales que habían asolado su isla.

¡Qué distantes y, sin embargo, qué cercanos estaban estos dos galardonados! De esto me di cuenta en una segunda lectura. Coetzee no nombraba a Defoe, pero su cuento era un ensamblaje de varias de sus obras: El Gran Tour por la Isla, Las Aventuras de Robinson Crusoe, El Diario del Año de la Peste. Coetzee había extraído pasajes para después limitarse a tejerlos. Él también -pensé- está dando sus agradecimientos. Si Brodsky habló de cómo su generación buscó la continuidad de la cultura por medio de la reconstrucción intuitiva de las formas y figuras de la tradición, reanimándolas con nuevos contenidos, eso mismo hacía Coetzee, al darles vida a los personajes e historias de Defoe en su cuento, al dejarlos caminar sobre sus hojas blancas. Desde esta perspectiva, ¿no era el acto creativo un acto de repetición de un conjunto de buenas anécdotas? ¿No nos estaba insinuando Coetzee, mediante el perico de Robinson, que el escritor es un ave entrenada para decir ciertas cosas? Las similitudes y correspondencias entre los dos galardonados no terminaban ahí. En la parte final de su discurso, Brodsky decía que la poesía gravitaba entre el conocimiento analítico, intuitivo y el lenguaje de los profetas: la revelación. Algo similar se iba filtrando por la manera en que Coetzee unía las anécdotas de su cuento, por esa progresión que aceleraba el paso de su pluma hasta hacer que su protagonista escribiera palabras que ni siquiera él podía reconocer como propias:

'Death himself on his pale horse': those are words he would not think of. Only when he yields himself up to this man of his do such words come. $^{2}$

No eran dos discursos tan diferentes. El gran tema del cuento de Coetzee era también el misterio de la creación y había que aplaudirle

\footnotetext{
${ }^{2}$ J. M. Coetzee, He and his man, (www.nobelprize, org.), december 7, 2003, p. 4.
} 
no sólo por velar los secretos de la primera y, a la hora de revelarlos, hacerlo con toda la fuerza del ejemplo, sino por la buena costumbre de rendirle honor a su maestros haciéndolos personajes de sus narraciones. ¿Pero era tan importante Defoe en la obra de Coetzee o sólo un señuelo, como los patos de Linconlshire de su cuento, un señuelo para atrapar lectores y conducirnos por senderos más y más estrechos?

\section{Novela y modernidad}

Un valle y una mesa. Estas son las dos imágenes que utiliza Forster para hablar de la novela y los novelistas en la primera de sus conferencias sobre Aspectos de la Novela. El género de la novela como un amplísimo y accidentado valle, irrigado por muchos cauces, sólo limitado por dos cadenas montañosas: la historia y la poesía. Y la relación de los escritores de todos los tiempos sobre una mesa grande, redonda, atemporal, donde trabajan frente a frente viéndose las caras. ${ }^{3}$ ¿Dónde estaban en esta mesa Defoe y Coetzee? ¿Servían estos escenarios para entender mejor su relación? La fuerza argumental detrás de ambas imágenes es la de hablar de la novela como algo vivo. Como escritor Forster entiende que el precio de diseccionar y poner fecha de caducidad a las novelas es muy alto. Para estudiarlas minuciosamente las atrapamos, la inmovilizamos, sin darnos cuenta que perdemos lo más valioso que hay en ellas. En nuestras manos las obras se convierten en seres sin vida, objetos muertos, piezas de museo. El amplio valle intenta proteger la vitalidad, riqueza y variedad de la novela frente a la simplificación y la homogenización. La mesa reivindica su actualidad contra el historicismo característico de escuelas y academias, contra el afán de agrupar a los escritores y encerrarlos en corrientes y épocas. Sin embargo, dejar fuera el tiempo en el caso de Defoe y Coetzee me parecía una operación igualmente peligrosa. Sin el horizonte de la historia existía el riesgo de perder ese aire de novedad con que esta-

\footnotetext{
${ }^{3}$ Forster, Aspectos de la Novela, 1990, Madrid, Debate, p. 9-30.
} 
ban imbuidas las obras de estos dos novelistas, frente a muchas otras. Justamente en la historia y en museos era en lo que pensaba cuando leía Las Aventuras de Robinson Crusoe, o El Diario del Año de la Peste, especialmente en los cuadros holandeses del siglo XVI y XVII que había visto en el Museo del Prado y en la National Gallery. Las novelas de Defoe y las pinturas de los maestros de Deft o de Amberes compartían una frescura, una soltura inusual, propia de quien contempla el mundo en toda su extrañeza desde un nuevo punto de vista; en las dos encontraba el placer por nombrar y describir objetos cotidianos: panes, pescados, conejos, vajillas y canastas. Los colores y la tinta se detenían en descripciones pormenorizadas. En ellos el protagonismo de los dioses, de los héroes o de las vírgenes, se desvanecía. Su lugar era ocupado por comerciantes y cocineras, hombres ordinarios y, al mismo tiempo, irrepetibles, únicos. Me parecía que, tal vez sin proponérselo, Defoe recogía para las letras los frutos de la revolución protestante que marcaba la entrada a una nueva época. Para mí sus novelas aparecían asociadas al proyecto moderno. Defoe se había convertido en uno de los pioneros de este amplio territorio a través de combinar y mezclar en el mismo plano lo espiritual y lo material, el estilo alto con que eran tratados los héroes de la tragedia y el estilo bajo de los antihéroes de la comedia. A diferencia de Forster, yo no podía pensar en las novelas de Defoe ni en las de Coetzee sin ubicarlas históricamente. ${ }^{4}$

Mientras escribía este texto, una amiga me prestó una de las últimas novelas del recién fallecido Saúl Bellow. Siguiendo a su protagonista, Ravelstein, sentí que caminaba ante el mismo horizonte que había inaugurado Defoe en la tradición de las letras inglesas. Ravelstein era una lumbrera de universidad, que seguía hablando del amor en términos de Platón, que defendía la herencia de Atenas y Jerusalén contra

${ }^{4}$ Coetzee asocia cada una de las tres características fundacionales de la novela a sus respectivos pioneros: el empirismo a Defoe; la mezcla de lo alto y lo bajo a Fielding; y la apropiación de la tradición del Romance, sin la maquinaria supra natural, a Richardson. J. M. Coetzee, Stranger Shores, Essays 1986-1999, “Daniel Defoe, Robinson Crusoe”, 2002, Londres, Vintage. 
el mundo burgués y, al mismo tiempo, se pasaba gran parte de la vida comprando las cosas más banales (relojes, corbatas, abrigos finos). En él redescubría trescientos años después que la novela mantenía esa unión de lo bajo y de lo alto. La novela tenía la capacidad de trasmitir el ideal de la condición humana, la aspiración a lo mejor conviviendo con la imperfección propia de nuestra especie. ${ }^{5}$

Sólo recordando esto me parecía que era posible internarse en el valle de Forster. Tal vez en este paisaje pensó Coetzee cuando, en su prólogo de 1999 a la edición de Oxford de Las Aventuras de Robinson Crusoe, situó a Defoe muy cerca de la cordillera de la historia. No a la historia en el sentido que lo han estado tantas novelas que tratan momentos o personajes históricos, sino en el sentido de que sus narraciones imitan la textura de la realidad, aparecen como confesiones de gente real que han sido únicamente transcritas por el autor. Robinson, Roxana, Moll Flanders y casi todas sus novelas comienzan con la fórmula de "la verdadera historia de..." Pero esto no es suficiente para lograr esa difícil textura de verosimilitud -nos dice Coetzee- como tampoco la primera persona que le confiere cierto aire de confesión a la narración. Mediante las descripciones de los objetos y de las acciones, Defoe nos da una viveza inusitada, nos trasmite esa sensación de los hechos, de lo que realmente sucede. En este sentido, Coetzee nos recuerda: "El Diario del Año de la Peste está lo más cerca que uno puede estar de la falsificación de un documento histórico antes de comenzar a jugar con tinta y papel viejo." 6

¿Por qué este anhelo de veracidad? ¿Qué motivos tenía para afirmar la dimensión verídica de sus historias? ¿Son los motivos meramente comerciales del Defoe periodista que ha descubierto en esos primeros periódicos de la historia el ansia de la gente por los hechos, la forma en que la verdad se puede vender como pan caliente? ¿O es expresión de

${ }^{5}$ Una interesante reflexión desde la filosofía moral de la novela es el libro de ensayos de Martha Nussbaum, Love Knowledge, Essays on Philosophy and Literature, 1990, Nueva York, Oxford University Press.

${ }^{6}$ J. M. Coetzee, Stranger Shores, Essays 1986-1999, "Daniel Defoe, Robinson Crusoe", 2002, Londres, Vintage, p. 22. 
una forma atenuada de psicosis, del Defoe perseguido por prestamistas y autoridades, que ha sufrido el tormento de la picana y ha pasado temporadas infernales en la cárcel de Newgate y que realmente cree que sus fantasías son verdad ${ }^{7}$ Defoe no nos dice nada de sus motivos. Pero contra la acusación de que Las Aventuras de Robinson son una mera fantasía se defiende su protagonista en Serious Reflections. Ahí Robinson acepta que su narración es alegórica sólo para sostener más adelante su realidad histórica. La fidelidad a este argumento no tiene que ver sólo, como explica Coetzee, con la intención de mantener la fachada biográfica de sus obras como anzuelo comercial. En la misma serie de ideas Defoe/Robinson dirá, de manera muy sintomática, que en sus veintiséis años de vida en la isla nunca se sintió tan solo como en Londres en medio de la multitud. Tal vez Robinson ha tomado la pluma desde esa otra dimensión a la que pertenece para recordarnos que no existe una sola realidad. Nos está diciendo que, muy cerca de la realidad objetiva, de los hechos, está esa realidad subjetiva de la percepción y los sentimientos. Su identidad ficticia y los argumentos que surgen de ella nos han conducido a esa frontera y cuando estamos parados ahí, nos pregunta ¿qué trasmite con más realidad el sentimiento 94 de soledad que un hombre puede sufrir en el corazón de Londres: la vida en una isla desierta o las calles de la metrópoli?

Más allá de la discusión filosófica sobre si el criterio válido para juzgar sentimientos y percepciones es la dicotomía realidad-ficción, Coetzee admira el resultado literario que dicha pretensión tiene en las obras de Defoe y sigue las dos rutas que su antecesor inauguró. Ambas tienen el efecto de hacer desaparecer al autor y esconder la factura literaria. En su lugar se quedan los hechos y su personaje. Son dos caminos, el primero, es lo que Ian Watts llamó realismo formal ${ }^{8} \mathrm{y}$, que el propio Coetzee matizó de dos maneras: empirismo desnudo (prólogo a Robinson) o empirismo modesto (Elizabeth Costello), entendiendo por

${ }^{7}$ Paula Backscheider, Daniel Defoe his Life, 1995, London, The Johns Hopkins University Press.

${ }^{8}$ Ian Watts, The Rise of the Novel: studies in Defoe, Richardson and Fielding, 2001, Berkeley, University of California Press. 
ello "descripciones precisas, realizadas con tres o cuatro apuntes poderosos, que crean una especie de campo magnético, vibrante, que en sus mejores momentos, logra esa transfiguración propia de la poesía”. El segundo camino es el del travestismo o ventrilocuismo, la habilidad para adentrarse en la piel del otro, para sentir el mundo desde sus sentidos y pensarlo desde su cabeza. Esta técnica que encontramos con toda su naturalidad y frescura en Moll Flanders, Robinson y el informante del Diario, en los protagonistas de Coetzee se ha convertido en un arte perfeccionado. A partir de su tercera novela La vida y época de Michael $K$ será un rasgo distintivo de su alta factura literaria. Se trata de experimentar a través del personaje distintos estados, tocando los límites de su cuerpo, sus rincones y haciendo preguntas desde adentro: ¿cómo se siente K cuando enferma?, ¿y cuándo deja de comer durante días?, ¿qué le pasaría a su cuerpo y a sus ideas si sólo se alimentara de insectos?, ¿qué pasaría con sus sentidos si viera sólo de noche?, ¿a qué sabría una calabaza después de días de ayuno o qué textura le quedaría en la boca después de días de diarrea?

Ventrilocuismo y empirismo son los dos planos que comparten Coetzee y Defoe en el territorio de la novela. A partir de aquí Coetzee avanza en el tratamiento de las emociones que, como nos dice, todavía en Defoe pertenece al análisis de los movimientos del alma descritos por la terapéutica cristiana, para ser propiamente modernos. En sus novelas Coetzee trabajará con ese realismo posterior que revela la vida interior de los personajes a través de gestos inconscientes, de diálogos internos o externos, y de acciones cuyo significado escapa a sus propios protagonistas. Pero es interesante notar que la propia obra de Coetzee muestra cómo estos sucesivos pasos sólo se mantienen sobre el piso que ha recorrido Defoe. Sus primeras novelas avanzan demasiado arriba, en la vida inconsciente o inmaterial hasta tal punto que En Medio de Ninguna Parte (In the Heart of the Country) se convierte en un amasijo de reflexiones que se torna un pesado monólogo para el lector. En algún sentido, la obra de Coetzee avanza retrocediendo. En la medida que regresa a los principios de la tradición realista le es posible extender sus elementos más modernos; entre más recorre 
ese piso empírico de la narración, se eleva con más fuerza. En este sentido, su literatura tiene la extrañeza de ser una forma de arrastrarse por la cordillera de la historia y, en la medida que se abandona a sus ínfimos detalles, aparece del otro lado, como una mota de polvo que ha remontado el largo valle hasta alcanzar la cordillera de la poesía. Aquí radica el valor de su escritura. Como lo mostró la noche de los premios Nobel su oficio es el humilde oficio de contar historias. Nada de discursos - nos diría- esto es lo que sé hacer señores. Por eso me tienen frente a ustedes, urbi et orbe: es simplemente otra forma de vida, ni mejor ni peor que otras, no necesita defensa. Y sin embargo, en su lento peregrinar Coetzee arriba al mismo lugar que Brodsky. De pronto, la literatura de Coetzee parece ser el recorrido por esas grandes extensiones africanas, las largas caminatas de alguien que ha aprendido a andar con ligereza. El contar se convierte en una forma de abandono, de exploración lenta, sensorial de las heridas; una forma de palpar la oscuridad e iluminarla con los pequeños y efímeros destellos de epifanías.

\section{La lengua de Viernes}

Lo que culminaría bajo la forma de un cuento la noche de los premios Nobel, comenzaría en 1986 con una novela. Foe es la versión de Coetzee de la historia de la isla de Robinson, junto con una reflexión sobre su composición. Pero antes de hablar de la novela me gustaría decir que más allá de los tratamientos abiertos (la novela de 1986, el ensayo de 1999 y el cuento de 2003), Robinson alimenta como un afluente oscuro y subterráneo la literatura de Coetzee. Los protagonistas del resto de sus novelas parecen por momentos variaciones del protagonista de Defoe. Magda, Michael K, el Maestro de Petersburgo, el Magistrado de Esperando a los Bárbaros, el maestro de Desgracia, todos ellos viven, sienten y piensan como náufragos en determinados momentos. A todos ellos, la guerra, la enfermedad u otros incidentes los arrojan fuera de la ciudad, lejos de la vida en sociedad. Coetzee 
reconoce en su precursor al primer novelista que trata magistralmente el tema de la soledad en su historia-alegoría de la isla desierta. Tal vez por esta razón Robinson acompañará como una sombra a cada uno de sus protagonistas. Por ello su cuento en la ceremonia de los premios Nobel no es un viejo material que desempolva y presenta como nuevo frente a su clase, sino el gran cauce que ha nutrido su obra, brotando en ocasiones a la superficie, pero manteniéndose la mayoría del tiempo, fresco, protegido, alimentándolo bajo tierra. Eso explica que el cuento de Coetzee sea una exhibición de virtuosismo, que sin embargo tiene un gran ausente: Viernes. Cuando Robinson lo menciona sólo lo hace de paso. Sus pericos ocupan más espacio. Esto tal vez se debe a que si bien, como lo mostró Coetzee, el cuento puede caminar hacia la poesía, es incapaz de retratar esas realidades más complejas, podríamos decir dialógicas o intersubjetivas que la novela por su naturaleza y extensión logra representar. Sin embargo, Robinson no hubiera fascinado a Coetzee si su vida en la isla no hubiera estado marcada por las incursiones de los caníbales, y en especial por la presencia de Viernes. Siguiendo a su maestro, la soledad para Coetzee siempre es una bestia de dos cabezas. Junto al yo siempre aparece el otro. Los protagonistas de Coetzee aparecen muy a menudo en esta forma de binomios, con un otro con el que establecen relaciones punteadas por la ambigüedad, entre el poder y el entendimiento, el miedo y el deseo. Es el caso claro de K (Vida y Época...) y el doctor, el magistrado y la salvaje (Esperando a los Bárbaros), de la enferma de cáncer y el vagabundo negro (La Edad de Hierro). Al problematizar la relación con el otro, Coetzee aborda los lazos de poder que, en muchas ocasiones, aparecen enmascarados con otros nombres. Sus protagonistas se esfuerzan por no engañarse a ellos mismos, sus aventuras interiores consisten -muchas veces- en navegar sobre las aguas de la ambigüedad, guiados por una especie de instinto ciego, de los dictados del corazón. Estas preocupaciones permiten inscribir la obra de Coetzee en los debates morales de la modernidad. Sus novelas no sólo se tratan del otro que está afuera sino de ese otro que está dentro del hombre y es distinto de su racionalidad. Se trata de ese espacio que desde los románticos 
se ha buscado proteger (muchas veces destruyéndolo paradójicamente a través de hipertrofias innecesarias y de operaciones totalizadoras) frente a los abusos de la razón instrumental, bajo muchos nombres, bajo muchas formas: la fantasía, el sentimiento, la espontaneidad, lo extático, la locura. ${ }^{9}$ Si bien es cierto que en Coetzee hay un lugar para estas distintas realidades podemos encontrar una veta principal que es la defensa del cuerpo como aquello esencial e irreducible, esa dimensión que compartimos con los animales.

Al hablar de la novela en estos términos y enmarcar la obra de Coetzee dentro de los debates filosóficos-morales de la modernidad, es necesario adentrarse de ese otro lado oculto, el documento de barbarie a la sombra del documento de civilización. Foe tiene todos los rasgos de un ejercicio de rescate crítico de la tradición. Junto al homenaje hay denuncia. Coetzee circunscribe la historia de la isla desde la llegada de Susan hasta la muerte de Cruso en el barco que los rescata. Con ello en términos ideológicos rasura la propaganda colonialista y mercantilista de su antecesor. Pues cuando Susan, Cruso y Viernes son rescatados nadie se queda fundando una colonia. Tal vez se debe a que la mesa de Forster donde se miran Coetzee y Defoe puede ser atemporal, pero ellos son hombres históricos que escriben desde distintos tiempos y lugares. Defoe es un inglés en el corazón y en la semilla del imperio, Coetzee un sudafricano que habita en las antípodas, en la última y tal vez más cruel de las colonias, alguien que se ha alimentado de los frutos amargos y podridos de la empresa colonial que Defoe, sin timidez, celebraba. Es esta historia la que hace que Coetzee ponga un signo de interrogación al final de la novela de Defoe, un signo de interrogación que contagia al proyecto de modernidad con el que antes asociamos la novela. Está muy bien la combinación de lo alto y lo bajo -nos diría Coetzee- en el Robinson inglés y en el Ravelstein norteamericano, no es difícil estar de acuerdo en el ideal de individuo para los que viven en sociedades ricas, para un Ravelstein situado en

${ }^{9}$ Jürgen Habermas, The Philosophical Discourse of Modernity, Twelve Lectures, 1990, Massachusetts, The MIT Press Cambridge. 
la ciudad que cristalizó el proyecto de reforma espiritual iniciada en Europa, en los años de Defoe; pero, ¿no es un poco más compleja la cuestión? -preguntaría-, ¿qué pasa cuando nos salimos del mundo de la universidad y vemos que, en otros contextos políticos, lo bajo y lo alto toman formas mucho más perversas? ¿Qué le pasaría a Ravelstein si fuera arrojado más allá de la ciudad, fuera los límites de su querida pólis? ¿Qué transformaciones sufriría si tuviera que habitar una de estas islas desiertas? ¿No es, a fin de cuentas, la geografía e historia humana un archipiélago de esta clase de islas?

Esta perspectiva histórica explica por qué una vez que Cruso muere en la novela, la vida de Susan en Inglaterra gira en torno a dos problemas: ¿cómo contar la historia de la isla, y cómo entender y comunicarse con Viernes? Estos dos problemas no están separados, la historia de la isla - como le interesa contarla a Susan- está inevitablemente unida a la identidad de Viernes, a la forma cómo vive y siente. Así, en el centro de la novela yace el reclamo de Coetzee por la decisión de Defoe de convertir a Viernes y a los aborígenes en caníbales, y por la flagrante imposición del punto de vista de Robinson sobre el de Viernes:

I was greatly delighted with him, and made it my business to teach him everything that was proper to make him useful, handy, and helpful; but especially to make him speak, and understand me when I spoke; and he was the aptest scholar there ever was. ${ }^{10}$

El Viernes de Coetzee es muy parecido al de Defoe, sólo hay una pequeña diferencia, de la cual Susan no se da cuenta hasta que Cruso lo hace cantar y le abre la boca: le han amputado la lengua. No son Viernes diferentes. Con o sin lengua, ninguno de los dos puede contar su versión, su historia. A ambos se les imponen verdades. Otros traducen lo que piensan y lo que sienten. Lo único que ha hecho Coetzee es hacer explícito el acto de violencia. Este es el reclamo literario-humano

${ }^{10}$ Daniel Defoe, Robinson Crusoe. Vida y extrañas y sorprendentes aventuras de Robinson Crusoe escritas por él mismo, 1975, Barcelona, Lumen, vol. I, trad. Julio Cortazar, p. 197. Utilizado por Coetzee como epígrafe para su cuento Él y su hombre. 
de Coetzee a Defoe. Durante la novela, Susan intentará una y otra vez comunicarse con Viernes sin lograrlo, por lo cual la historia de la isla siempre permanecerá incompleta, sin el punto de vista de ese otro que también vivió, sintió y sufrió en ella. El misterio de quién le cortó la lengua a Viernes permanecerá hasta el final, sin que Susan pueda resolverlo. Sin embargo, uno sospecha que la culpa la tiene Defoe. Se trata de un defecto de nacimiento. Defoe creó a Viernes sin lengua. 